\title{
CHEMICAL PROPERTIES OF COMETARY DUST AND A NOTE ON CARBON ISOTOPES
}

\author{
ELMAR K. JESSBERGER AND JOCHEN KISSEL \\ Max-Planck-Institut für Kernphysik \\ P.O. Box 103980 D-6900 Heidelberg
}

\begin{abstract}
On board the space probes Giotto and VEGAs and 2, which were sent through the coma of comet Halley, were the mass spectrometers PIA and PUMAs 1 and 2 for the in situ analysis of cometary dust. This paper summarizes the results obtained up to now, about four years after the flybys. It is sought to make the reader aware of the significance, but also of the limitations, of these unprecedented data gathered within a few hundred seconds with an innovative instrument about $1.5 \times 10^{8} \mathrm{~km}$ away from Earth. The first part of this paper shows how the bulk properties of the dust are derived-the main constituents CHON and silicates, the core-mantle structure, the molecular composition of the organic component, the average composition of the dust and of the whole comet, and the gas/dust ratio. The second part reviews what can safely be said about the properties of the individual grains--their similarity to a certain class of interplanetary dust particles and their distinction from others, and their density and masses. The final part of this paper shows that some cometary grains contain isotopically ultra-light carbon $\left({ }^{12} \mathrm{C} /{ }^{13} \mathrm{C}\right.$ up to 5000 ), a finding that is significantly substantiated by reports of similar carbon isotopic composition in meteoritic graphite.
\end{abstract}

\section{Introduction}

It is commonly believed that comets were formed within the solar system from the same initial dust and gas nebula as were the larger bodies such as the planets. But because of the comets' small size, which implies the absence of large-scale geologic differentiation and mixing processes, one may expect that the isotopic, chemical, and molecular characteristics of the presolar material and its heterogeneity are best preserved in comets. Thus, experiments to study the composition of dust and gas in the coma were central in the missions to comet Halley in 1986. Here an overview is given on results extracted so far on the dust composition from the PIA and PUMAs 1 and 2 experiments on board Giotto and VEGAs and 2.

The experiments' time-of-flight impact-ionization mass spectrometers, with two flight sections separated by a reflector unit, have been described in detail by Kissel (1986). A schematic of the instrument is given in Figure 1. Solid dust particles impinge upon a clean target surface-Ag or Ag-doped Pt-with the Giotto and VEGAs and 2 encounter 


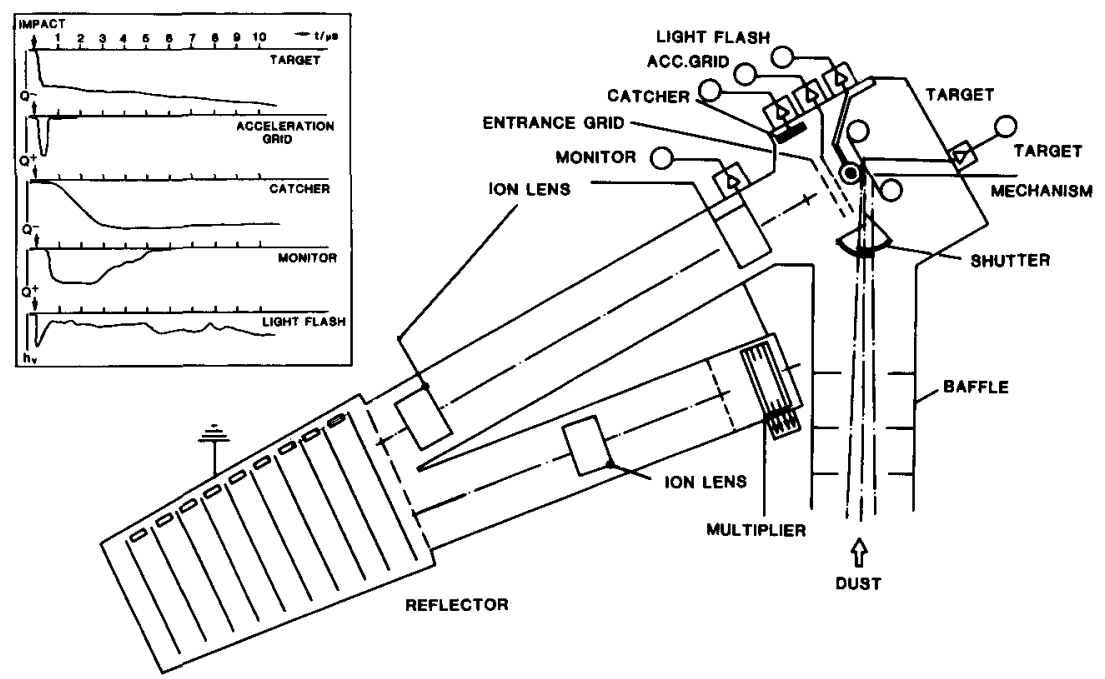

Figure 1. Schematic view of the particulate impact analyzers on board Giotto and VEGAs and 2. The inset shows characteristic front-end signals. From Kissel (1986).

speed of 69 and $79 \mathrm{~km} / \mathrm{sec}$, respectively. Upon impact, the particle and some target material are vaporized and partly ionized. Positive ions are extracted by a $1-\mathrm{kV}$ grid and subsequently separated according to the mass/charge-ratio in a time-of-flight spectrometer:

$$
\mathrm{m} / \mathrm{q}=2 \cdot \mathrm{s}^{2} \cdot \mathrm{U} \cdot \mathrm{t}^{2}
$$

where $\mathrm{m}=$ mass, $\mathrm{q}=$ charge, $\mathrm{s}=$ flight-path length, $\mathrm{U}=$ acceleration voltage, and $\mathrm{t}=$ flight duration. To increase the mass resolution to $\mathrm{m} / \delta \mathrm{m} \approx 150$, an ion-reflector counterbalances possible initial ion energy differences. The ions are detected by a particle photomultiplier at the end of the drift tube. The actual peak heights are converted on board to their logarithms to cover a dynamic range of 5 decades.

Measured quantities are the flight duration-the time difference between the impact start pulse given by various front-end detectors (Figure 1) and the ion arrival time at the multiplier - and the peak height. The flight duration is proportional to $V_{\mathrm{m}}$, so a mass scale can be calculated in later computer-aided data analysis. Because the data transmission rate is limited, the raw data are received on Earth in differently compressed modes (see below).

The mass spectra procured by PIA and PUMAs 1 and 2 are the first and only spectra obtained directly from cometary grains and thus are exceedingly precious. One should, however, be aware that the quality of the data does not resemble that of terrestrial laboratory data. Some of the limitations, which will be described at the proper passages in the following text, include: 
- The unavoidable onboard data compression.

- The inability to calibrate the experiments with appropriate particles having proper impact velocities.

- The difficulty in describing completely and from first principles the physics of the ionization mechanism.

- The fact that no repetition of any measurement near the comet will be possible in the near future.

It also should be noted that the mass of most analyzed particles is very small, on the order of $10^{-14} \mathrm{~g}$, or a few tenth of a micrometer in diameter (Maas et al., 1990).

Previous publications from the experimenters' group on various aspects of the PIA and PUMAs 1 and 2 results are, in the approximate order of their appearance:

Kissel et al. (1986a, b)

Clark et al. (1986)

Solc et al. (1986)

Brownlee et al. (1987),

Jessberger and Kissel (1987)

Mukhin et al. (1987)

Kissel and Krueger (1987a)

Solc et al. (1987)

Lawler et al. (1989a, b)

Krueger and Kissel (1989)

Maas et al. (1990)

Rietmeijer et al. (1989)

Krueger et al. (1990)
Jessberger et al. (1986)

Sagdeev et al. (1986)

Wäsch (1986)

Clark et al. (1987)

Langevin et al. (1987a, b)

Jessberger et al. (1987)

Krueger and Kissel (1987)

Jessberger et al. (1988)

Jessberger et al. (1989)

Solc et al. (1989)

Mukhin et al. (1989a, b)

Grün and Jessberger (1990)

\section{Bulk Properties of Halley's Dust}

Table 1 gives the ion abundances normalized to $\mathrm{Mg}$ that were obtained from all PUMAs 1 and 2 and PIA spectra evaluations performed so far, to allow comparison of the results. Because of limited data transfer rates from the spacecraft to Earth, most spectra were transmitted in highly compressed modes and have to be deconvolved on Earth. These are the so-called mode-1, mode-2, and mode-3 spectra (Kissel, 1986). Every 30th spectrum, however, was transmitted in a transient recorder-like mode (mode- 0 ) with about four data points per mass unit. Mode- 0 spectra allow for rigorous identification of elements using their isotopic composition (Jessberger et al., 1988, 1989). To a limited extent, this also has been done with the higher mode spectra in the analysis by Lawler et al. (1989a), while in the studies of Langevin et al. (1987a) and Solc et al. (1989), no such check using the isotopic composition was applied and the ion intensity at the mass unit of the major isotope of the elements, regardless of possible molecular interferences, was taken to quantify the element abundance.

The data in Table 1 are given separately for short and long spectra. Short spectra were obtained when the reflector voltages allowed the passage of ions with initial energies of up to $150 \mathrm{ev}$, which was always the case for the PIA instrument. In PUMAs 1 and 2, the reflector voltages were switched every 30 seconds, alternately letting ions pass with initial energies of up to $150 \mathrm{ev}$ (short spectra) and up to $50 \mathrm{ev}$ (long spectra), respectively. 
Table 1. Mean ion abundances obtained in four independent analyses of PUMAs 1 and 2 and PIA mass-spectra. Abundances are normalized to $\mathrm{Mg}=100$. See the text for further details.

$\begin{array}{lllllllll}\mathrm{H} & \mathrm{C} & \mathrm{N} & \mathrm{O} & \mathrm{Si} & \mathrm{S} & \mathrm{Ca} & \mathrm{Fe}\end{array}$

(Langevin et al., 1987)

$\begin{array}{llllllllll}\text { mode } 1-3 & \text { short } & 240 & 140 & 7.1 & 195 & 48 & 7.6 & 2.4 & 9.5\end{array}$

(Langevin et al., 1987)

$\begin{array}{llllllllll}\text { mode 1-3 } & \text { short } & 1100 & 440 & - & 260 & 55 & 17 & 9.5 & 18\end{array}$

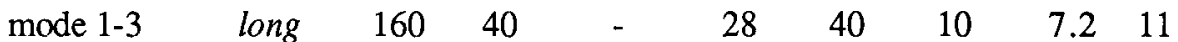

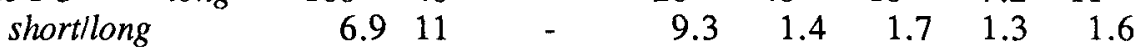

(Jessberger et al., 1988)

$\begin{array}{llrrrrrrrr}\text { mode 0 } & \text { short } & 8200 & 710 & 27 & 440 & 79 & 19 & 3.8 & 20 \\ \text { mode 0 } & \text { long } & 280 & 85 & 1 & 54 & 49 & 15 & 6.2 & 20\end{array}$

$\begin{array}{lrrrrrrrr}\text { shortllong } & 29 & 8.4 & 27 & 8.2 & 1.6 & 1.3 & 0.6 & 1\end{array}$

(Lawler et al., 1989)

$\begin{array}{lllrrrrrrr}\text { mode 1-3 } & \text { short } & - & 180 & - & 200 & 91 & 30 & 12 & 23 \\ \text { mode 1-3 } & \text { long } & - & 40 & - & 44 & 63 & 20 & 10 & 25\end{array}$

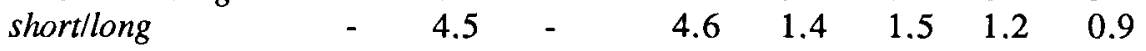

(Solc et al., 1989)

$\begin{array}{llrllllllr}\text { mode 1 } & \text { short } & 580 & 177 & 10 & 82 & 52 & 8.5 & 3.8 & 9 \\ \text { mode 2 } & \text { short } & 3040 & 445 & 27 & 325 & 74 & 9.3 & 6.0 & 12 \\ \text { mode 3 } & \text { short } & 1940 & 307 & 6.8 & 155 & 50 & 10 & 4.2 & 27 \\ \text { ave. mode 1-3 } & \text { short } & 1140 & 265 & 11 & 144 & 54 & 9.2 & 4.3 & 17\end{array}$

(Langevin et al., 1987)

$\begin{array}{llllllllll}\text { mode 1-3 } & \text { short } & 170 & 120 & 5.3 & 200 & 67 & 19 & 8.7 & 33\end{array}$

$\begin{array}{lllllllll}\text { mode 1-3 long } & 49 & 37 & 2.3 & 57 & 57 & 25 & 9.1 & 34\end{array}$

$\begin{array}{lllllllll}\text { shortllong } & 3.5 & 3.2 & 2.3 & 3.5 & 1.2 & 0.8 & 1.0 & 1.0\end{array}$


Another difference between the instruments-the different targets-also has to be considered: the PIA target was an Ag-doped Pt-foil, while PUMA 1 had a corrugated Ag-sheet and PUMA 2 had a flat Ag-sheet (Kissel, 1986; Langevin et al., 1987a). As yet, however, the influences of the different target materials and geometries have not been fully explored.

The data of the short PUMA 1 spectra, which permit the direct comparison of four different studies, show a remarkable similarity of results despite the different approaches. The evaluation of the mode- 0 spectra (Jessberger et al., 1988) tends to higher Mg-normalized ion abundances because the isotopic check of the reference element $\mathrm{Mg}$ is stricter here than in the higher modes: especially the intensity ratio $24 / 25$ has been found to be excessive due to $\mathrm{C}_{2}{ }^{+}$-interference (Jessberger and Kissel, 1987), thus easily increasing the apparent $\mathrm{Mg}$ ion abundance and lowering the relative ion abundances of the other elements. By and large, the average ion abundances of the four studies agree within a factor of about three, and the important elements $\mathrm{Fe}$ and $\mathrm{Si}$ (see below) agree to a considerably greater degree.

Table 1 also lists the ratios short/long of the ion abundances, normalized to $\mathrm{Mg}$, from the short and long spectra. For PUMA 1, these ratios are around unity in the narrow ranges of $1.4-1.6$ for $\mathrm{Si}, 1.3-1.7$ for $\mathrm{S}, 0.6-1.3$ for $\mathrm{Ca}, 0.9-1.6$ for $\mathrm{Fe}$, and 1.0, by definition, for $\mathrm{Mg}$. Similar values are also found for PUMA 2. The light volatile elements have the much higher ratios (for PUMA 1) of 7-29 for $\mathrm{H}, 4.5-11$ for $\mathrm{C}$, and $4.6-9.3$ for $\mathrm{O}$. The overabundance of the $\mathrm{CHON}$ ions in the short spectra compared with their abundance in the long spectra means that they are suppressed in the $50-\mathrm{eV}$ window relative to the $150-\mathrm{eV}$ window setting, while the ions from the rock-forming elements pass both windows with the same probability relative to the Mg ions. The short/long ratios for the CHON elements obtained from PUMA 1 in Langevin et al.'s (1987a) study are higher than those obtained from PUMA 2 by the same authors. It is possible that this difference is a reflection of the different target geometry, flat Ag-sheet (PUMA 2), and corrugated Agsheet (PUMA 1).

It has been shown by common factor analysis that overall the CHON elements group together, which also implies that most oxygen is not from the silicates, but from an organic phase (Jessberger et al., 1988, 1989). Early in the data analysis (Clarke et al., 1986), this fact already was interpreted to indicate the presence of two end-member particle types, CHON and silicates. Most Halley grains are mixtures of these two types.

The fact that the CHON ions have, on the average, a higher initial energy than the silicate ions led Krueger and Kissel (1987) to infer a core-mantle structure of the dust particles. The CHON ions from the refractory organic (Jessberger et al., 1987) mantles are thought to leave their place of origin after the impact with higher initial energies (up to $150 \mathrm{ev}$ ) on the average than do ions of the rock-forming elements from the grain cores. The existence of the previously postulated (Greenberg, 1982) core-mantle grains now seems to be substantiated by data.

Kissel and Krueger (1987a) performed a detailed analysis of the relatively minor molecular lines in the PUMA 1 spectra and inferred from them information on the molecular composition of the refractory organic component. Recently, Krueger et al. (1990) performed a combined analysis of the organic component in the dust (data from PUMA 1) and in the gas (data from PICCA on board Giotto). Their principal results were that the organics are "complex unsaturated polycondensates that split during coma-formation into a more refractory $\mathrm{C}=\mathrm{C}, \mathrm{C}-\mathrm{N}$-containing dust part and the more volatile $\mathrm{C}=\mathrm{C}, \mathrm{C}-\mathrm{O}-$ containing gas part." In another study, Krueger and Kissel (1989) discussed the role of comets for the 
origin of life and developed a new model in which both comets and early terrestrial surface characteristics together are prerequisites for life.

$\mathrm{Up}$ to this point, only ion abundances are discussed. The transition from ions to atoms requires the knowledge of ion yields. Certainly one would prefer to obtain those from calibration shots with projectiles of different chemical composition, size, and structure at the encounter speeds of 69 and $79 \mathrm{~km} / \mathrm{sec}$, respectively. As yet, this is technically impossible. Mukhin et al. (1988a, b) simply set the relative yields (of the rock-forming elements $\mathrm{Si}, \mathrm{Mg}$, and $\mathrm{Fe}$ ) to be equal-an unrealistic and non-physical approach. We prefer to use the relative ion yields derived for this type of instrument from secondary ion mass spectrometry (SIMS) yields and from calibration measurements made with particle speeds $<64 \mathrm{~km} / \mathrm{sec}$ (Kissel and Krueger, 1987; Krueger and Kissel, 1987). These yields are presumed to be accurate only within a factor of two, but they have the advantage of having been derived without bias. Although the yields for the rock-forming elements are given only for long spectra (Krueger, personal communication), we apply them for the short ones as well, which is justified by the short/long ratios around unity (Table 1). The yields for the CHON elements have been adjusted using the short/long ratios.

The average composition of Halley's dust and its derivation from ion abundances have been discussed by Jessberger et al. (1986, 1987, 1988). The Mg-normalized elemental composition of the dust is given in Table 2 . Also listed are the respective values for CI chondrites and the solar system (Anders and Grevesse, 1989). The rock-forming elements in Halley's dust are within a factor of two of being the same as in CI chondrites and the solar system. H, C, and $\mathrm{N}$ are more abundant than in $\mathrm{CI}$ chondrites, which are regarded as the most unaltered meteorites from the early solar system available for study in the laboratory. This can be viewed as implying that Halley's dust is less fractionated, i.e., more primitive, than CI chondrites.

The $\mathrm{C} / \mathrm{Mg}$ ratios decrease from 9.4 in the solar system (Anders and Grevesse, 1989 ) to 8.2 in Halley's dust (Table 2) and to 0.71 in CI chondrites (Anders and Grevesse, 1989). (Note that the C/Mg-value previously adopted by Anders and Ebihara (1982) was 11.3.) This sequence may reflect gas-dust fractionation before or during the formation of bodies more solid than Halley. The similarity of Halley's dust value and that of the solar system suggests that Halley as a whole is perhaps not fractionated and that the missing $C$ is in Halley's gas ( $\equiv$ ice) component. But how much gas, of the composition as determined by Krankowsky and Eberhard (1989), do we have to add to the dust to end up with a solarsystem-like whole comet? From data given by Krankowsky and Eberhard (1989), one can deduce the elemental $\mathrm{O} / \mathrm{C}$ ratio in the gas to be 5.9 and thus to be larger than in the dust, where it is 1.1 (see Table 2). Thus, a relatively small addition of $\mathrm{C}_{\text {gas }}$ will bring $(\mathrm{O} / \mathrm{Mg})_{\text {total }}$ closer to the solar value. If one wants to fit both $\mathrm{C}_{\text {total }}$ and $\mathrm{O}_{\text {total }}$ to the solar $\mathrm{C} / \mathrm{Mg}$ and $\mathrm{O} / \mathrm{Mg}$ ratios, one has to add to the dust abundances (Table 2) $2040 \mathrm{H}-, 200 \mathrm{C}-$, $55 \mathrm{~N}$-, and $1150 \mathrm{O}$-atoms (relative to the $100 \mathrm{Mg}$-atoms). The result is an estimate of the total composition of Halley's comet (Table 2). Compared with the solar system, the comet is depleted in $\mathrm{H}$ by a large factor (about 650 ), and in $\mathrm{N}$ by a factor of 3.1. The $\mathrm{N}$ deficiency in Halley has been independently found (and discussed) by Geiss (1987). The abundances of all other elements are the same-at least within a factor of two-in the solar system and in Halley's comet.

From the above consideration an estimate of the dust/gas weight ratio also results; this estimate is 1.7. In Grün and Jessberger (1989), a ratio of 1.1 was derived, which was based on the $\mathrm{C} / \mathrm{Mg}$-ratios alone. The change, however, is mainly due to the revised 
Table 2. Average atomic abundances of the elements in Halley's dust grains (Jessberger et al., 1988) and in the whole comet, dust, and ice (see text). 1

\begin{tabular}{|c|c|c|c|c|}
\hline \multirow{2}{*}{ Element } & \multicolumn{2}{|c|}{ Halley } & \multirow{2}{*}{ Solar System } & \multirow{2}{*}{ CI-Chondrites } \\
\hline & Dust & Dust and Ice & & \\
\hline $\mathrm{H} 2$ & 2,025 & 4,062 & $2,600,000$ & 492 \\
\hline $\mathrm{C}$ & 814 & 1,010 & 940 & 70.5 \\
\hline $\mathrm{N}$ & 42 & 95 & 291 & 5.6 \\
\hline $\mathrm{O}$ & 890 & 2,040 & 2,216 & 712 \\
\hline $\mathrm{Na}$ & 10 & 10 & 5.34 & 5.34 \\
\hline $\mathrm{Mg}$ & $=100$ & $=100$ & $=100$ & $=100$ \\
\hline $\mathrm{Al}$ & 6.8 & 6.8 & 7.91 & 7.91 \\
\hline $\mathrm{Si}$ & 185 & 185 & 93.1 & 93.1 \\
\hline $\mathrm{S}$ & 72 & 72 & 46.9 & 47.9 \\
\hline $\mathrm{K}$ & 0.2 & 0.2 & 0.35 & 0.35 \\
\hline $\mathrm{Ca}$ & 6.3 & 6.3 & 5.69 & 5.69 \\
\hline $\mathrm{Ti}$ & 0.4 & 0.4 & 0.223 & 0.223 \\
\hline $\mathrm{Cr}$ & 0.9 & 0.9 & 1.26 & 1.26 \\
\hline $\mathrm{Mn}$ & 0.5 & 0.5 & 0.89 & 0.89 \\
\hline $\mathrm{Fe}$ & 52 & 52 & 83.8 & 83.8 \\
\hline $\mathrm{Co}$ & 0.3 & 0.3 & 0.21 & 0.21 \\
\hline $\mathrm{Ni}$ & 4.1 & 4.1 & 4.59 & 4.59 \\
\hline
\end{tabular}

1 For comparison, the new solar system abundances and the CI-chondrite composition are also given (Anders and Grevesse, 1989). The solar photospheric abundances of the listed elements are practically indistinguishable from the solar system abundances, with the exception of $\mathrm{Fe}$, which has a photospheric abundance ratio of 123 (Anders and Grevesse, 1989).

2From short spectra only.

CHON-element abundances in the solar system (Anders and Grevesse, 1989). Considering the uncertainties of the present estimate, the dust/gas ratio of about 2 is reasonably close to other pre-flight (Delsemme, 1982) and post-flight (Lamy et al., 1990) estimates.

Some types of interplanetary dust particles (IDPs) are thought to be related to comets (Brownlee, 1985), and the few analyses of trace elements of IDPs yielded a striking enrichment (here, always meant relative to $\mathrm{CI}$ chondrites) of volatiles, especially of $\mathrm{Br}$ (van der Stap et al., 1986; Wallenwein et al., 1987; Antz et al., 1987; Sutton and Flynn, 1988), and an enrichment of volatile (non-CHON) elements in meteoroids was found from spectroscopic studies long before the Halley missions (Millman, 1977). It has already been 
abundance in CI chondrites. This may corroborate a genetic link of the volatile-rich IDPs and comets. However, the possibility has not yet been excluded that the volatile enrichments in IDPs are due to atmospheric contamination (Antz, 1988). The most recent study of trace elements in IDPs, in contrast to many of the studies mentioned above, indicated an enrichment of refractory elements, notably of the rare earth elements (Zolensky et al., 1989). It appears, however, that the enrichment factors are inversely correlated with the abundances of the respective elements, thus calling in question the validity of these new data. (One should add that the quantitative and non-destructive determination of typically less than $10^{8}$ atoms of an element is not an easy task.)

It was shown above that the rock-forming elements in Halley's dust are present , within a factor of two, in the same proportion, normalized to $\mathrm{Mg}$, as in the solar system (Table 2). This statement rests on the yields to convert measured ion intensities to atomic abundances that were determined prior to the Halley missions by Kissel and Krueger (1987b) and which are believed to be true within a factor of two. But close inspection of Table 2 reveals that some individual element ratios in Halley's dust and the solar system differ to a greater extent. This is most apparent in the case of the $\mathrm{Fe} / \mathrm{Si}$ ratio, which appears to be 0.28 in Halley's dust, has a value of 0.90 in the solar system and in CI chondrites, and in the solar photosphere has a new value of 1.32 (Anders and Grevesse, 1989). It has been discussed by Jessberger et al. (1988) and reiterated by Anders and Grevesse (1989) that a low $\mathrm{Fe} / \mathrm{Si}$ ratio in Halley's dust would exclude the pristine nature of Halley. Until now, the apparent cometary $\mathrm{Fe} / \mathrm{Si}$ ratio remains a puzzle, and for its solution, an independent determination of the ion yields would be desirable.

The uncertainty of a factor of two in the yields to convert ions to atoms precludes estimating in detail what kinds of minerals are present in Halley's dust. Therefore, Jessberger et al. (1988) and Lawler et al. (1989a), in order to allow the comparison of the composition of individual grains, argued that the yields to convert measured ion intensities to element abundances could perhaps also be derived from the assumption that Halley's dust has, on the average, the same composition as the solar system ( $\equiv$ cosmic). The justification for this assumption certainly is the fact that the average compositions were independently shown to be similar (Table 2). Why should they then not be the same? The pros and cons of the argument, which certainly involves circular reasoning, are discussed by Jessberger et al. (1988).

The details of the procedure to derive new yields based on cosmic abundances, however, are different in Jessberger et al. (1988) and Lawler et al. (1989a), respectively. Lawler et al. (1989a) assume that, on the average, the compositions of the individual grains are cosmic. Consequently, they equate the peaks in the frequency distribution of measured ion ratios with the respective cosmic element ratios to derive the new yields. Thus their procedure is number-dominated. Jessberger et al. (1988) start from the (maybe more plausible) concept that a fragment as big as possible would be characteristic for the whole comet. Therefore they mathematically reassemble the individual grains into a fragment: They calculate the sum of the number of ions of an element from all spectra, but, separately from short and long ones, normalize this to the respective sums of $\mathrm{Mg}$ ions, and equate the resulting ion ratios to the cosmic element $/ \mathrm{Mg}$ ratio. Thus this procedure is massdominated, as outlined by Jessberger et al. (1988). In this procedure, for example, small grains, which may stem from a chemically distinct and maybe especially friable dust component, do not prevail - this question was raised by one of the reviewers. Instead, larger grains control the yield determination, and they do it rightfully so, because they are more 
representative of the whole comet than small grains. The data presented in the following section have been obtained using the last procedure.

\section{Properties of Individual Grains}

An central question in comet research is "How homogeneous is the nucleus?" The answer would tell us about the homogeneity and about equilibrating processes within or before the early solar nebula. The mixture of ices and grains and the presence of two endmember grain types, refractory organic CHON and silicates, demonstrate disequilibrium. However, processes that formed the silicate cores onto which the refractory organic CHON mantles (and ices) later grew may already have been homogenizing. The compositional variability of the CHON component has been discussed by Clark $(1986,1987)$, Langevin et al. (1987a, b), Jessberger et al. (1988), and Grün and Jessberger (1989). This section will deal mainly with the information obtained regarding the major rock-forming elements $\mathrm{Mg}, \mathrm{Si}$, and $\mathrm{Fe}$.

A measure of the degree of chemical equilibrium is the distribution of the $\mathrm{Fe} /$ $(\mathrm{Fe}+\mathrm{Mg}$ ) ratios. In Brownlee et al. (1987), Jessberger et al. (1988, 1989), and Lawler et al. (1989a), it was demonstrated that Halley's dust is quite different from the matrix of carbonaceous chondrites and layer lattice silicate IDPs, which both show a narrow distribution around 0.5 . In contrast, cometary dust has a peak near $\mathrm{Fe} /(\mathrm{Fe}+\mathrm{Mg})=0$, followed by a broad distribution up to 1, which is similar to anhydrous IDPs (Bradley, 1988). It indicates the lack of chemical equilibrium among the grains and testifies to the pristine nature of the dust. A small contribution, about $10 \%$, of hydrous silicates, however, may be deduced from a hump at $\mathrm{Fe} /(\mathrm{Fe}+\mathrm{Mg}$ ) $=0.4-0.6$ (Jessberger et al., 1988; Lawler et al., 1989a).

Another indicator for equilibrium or disequilibrium is the distribution of the data in the ternary system $\mathrm{Mg}-\mathrm{Si}-\mathrm{Fe}$ (Figure 2). Hydrous material (carbonaceous chondrite matrix and layer lattice silicate IDPs) is concentrated in a narrow band vertically down from $\mathrm{Si}$ (Figure 2a), while anhydrous IDPs cluster around the Fe-poor pyroxene composition and, in addition, exhibit a broad, unspecific distribution (Figure 2b). This behavior is similar to Halley's dust composition (Figure 2c) and again demonstrates the unequilibrated nature of the comet (Jessberger et al., 1988, 1989). The same result has been obtained by Lawler et al. (1989a) using the diagram of $\mathrm{Fe} / \mathrm{Si}$ vs. $\mathrm{Mg} / \mathrm{Si}$. In the ternary system $(\mathrm{Ca}+\mathrm{Al})-\mathrm{Si}$ $(\mathrm{Mg}+\mathrm{Fe})$, Halley's dust data occupy a rather narrow field near the $\mathrm{Si}-(\mathrm{Mg}+\mathrm{Fe})$ tie line (Figure 3). Thus there are only a few, if any, Ca-Al-rich grains (Jessberger et al., 1988). This also becomes evident from a graph of $\mathrm{Al} / \mathrm{Mg}$ vs. $\mathrm{Ca} / \mathrm{Mg}$ lacking high values for either ratio (Jessberger et al., 1989).

Based on laboratory calibration studies of the impact ionization, time of flight, mass spectrometers with speeds up to $64 \mathrm{~km} / \mathrm{sec}$, and varying target-projectile combinations (Kissel and Krueger, 1987b), Maas et al. (1990) recently were able to derive the first meaningful density and size information on Halley's grains that hit the instrument and resulted in useful spectra. They also showed that the density of the grains is related to their overall chemical composition: Grains with atomic $(\mathrm{C}+\mathrm{O}) /(\mathrm{Mg}+\mathrm{Si}+\mathrm{Fe})$-ratios in the range of 0.01 to 10 (silicate-dominated) cluster around $2.5 \mathrm{~g} / \mathrm{cm}^{3}$, while those with larger ratios (CHON-dominated) have a mean density of $1 \mathrm{~g} / \mathrm{cm}^{3}$. CHON-dominated grains thus are fluffy, while silicate-dominated grains are more compact. The masses of the analyzed 


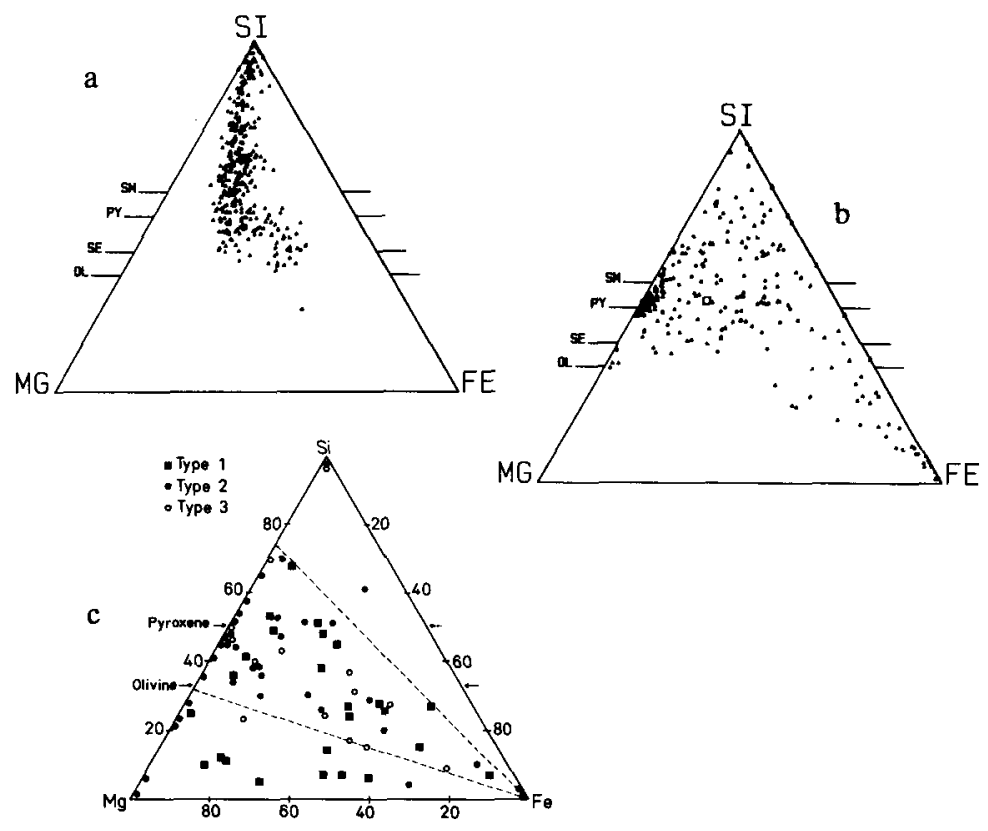

Figure 2. Ternary Mg-Si-Fe graphs (atom-\%) of (a) a layer lattice smectite interplanetary dust particle, (b) an anhydrous interplanetary dust particle, and (c) of a suite of Halley's dust grains. The data on IDPs were obtained by automated point count analyses of thinsectioned particles. Tie-lines show positions of important mafic silicates found in IDPs (OLivine, SErpentine, PYroxene, and SMectite). For the Halley data, the ion yields are adjusted such that the total $\mathrm{Si} / \mathrm{Mg}$ and $\mathrm{Fe} / \mathrm{Mg}$ ratios are cosmic. The types are a measure of the quality of the spectra, with type 1 being highest. The group of Halley grains near the Fe-poor pyroxene composition indicates the survival of primary $\mathrm{Mg}$-rich silicates, which may be taken as evidence for a low-temperature history of the grains and hence for the primitive nature of Halley's dust. From Bradley (1988) [Figures $2 a$ and $2 b$ ] and Jessberger et al., (1989) [Figure 2c].

particles range from $10^{-11}$ to $10^{-16} \mathrm{~g}$, with peaks in the mass distributions between $10^{-13}$ and $10^{-14} \mathrm{~g}$, for both silicate and CHON particles. Their results do not support the assumption that heavier grains are fluffier than the lighter ones. Maas et al. also demonstrate that the derived particle densities are in accord with the estimated mean density of Halley's nucleus, $0.2 \mathrm{~g} / \mathrm{cm}^{2}$ (Rickman, 1986).

\section{A Note on Isotopes}

Solc et al. $(1986,1987)$ and Jessberger et al. $(1987,1989)$ examined the information on isotopic compositions of the elements that is available from PUMA 1 spectra. It 


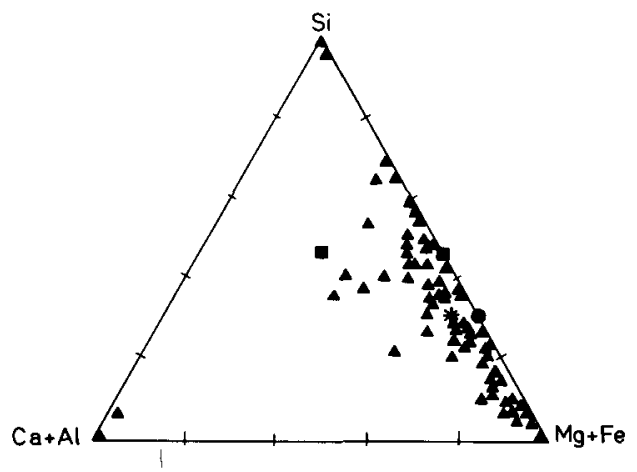

Figure 3. Ternary $(\mathrm{Ca}+\mathrm{Al})-\mathrm{Si}-(\mathrm{Mg}+\mathrm{Fe})$ graph of Halley's dust, which is shown by solid triangles. The star represents the cosmic composition, the solid circle represents the olivine point, and the two solid squares give the end members of the pyroxene group. The two grains with high $(\mathrm{Ca}+\mathrm{Al})$ are from disturbed spectra, and the extracted atom numbers are uncertain. If at all, there are only a very few grains in Halley's dust that resemble $\mathrm{Ca}, \mathrm{Al}$-rich inclusions found in carbonaceous chondrites and that are believed to have retained records from high-temperature episodes in the early solar system. From Jessberger et al. (1989).

was found that, in general, no element showed deviations from the normal solar system composition that could not easily be explained by molecular interferences. The only exception is carbon, in which the measured 12/13 intensity ratios range from about 1 to 5000 . Figure 4 shows the measured ion ratios versus the reciprocal ${ }^{12} \mathrm{C}$ intensity. The error bars are $2 \sigma$ of the count rate. The area in which data points would be normal within the uncertainty and the area in which the uncertainty is larger than the ratio are indicated. It would be intriguing to take values below normal $\left({ }^{12} \mathrm{C} /{ }^{13} \mathrm{C}=89.91\right)$ as being real in the light of the values that have been found in space (Audouze, 1977) and in meteorites, $4 \leq{ }^{12} \mathrm{C} /{ }^{13} \mathrm{C} \leq$ 120 (Zinner and Epstein, 1987; Ash et al., 1988; Zinner, 1989, Ming et al., 1989) as well as spectrographically in Halley's gas phase $\mathrm{CN},{ }^{12} \mathrm{C} /{ }^{13} \mathrm{C}=65$ (Wyckhoff and Lindholm, 1989). But since the resolution of the PIA and PUMA dust mass spectrometers is only about $\mathrm{m} / \delta \mathrm{m}=120$, the low values may be due to ${ }^{12} \mathrm{CH}^{+}$interference. For the high ratios, on the other hand, no such explanation can be given.

Ratios above about 120 had never been observed before anywhere in the world, and they existed only as a result of model calculations (Langer et al., 1984). Recently, however, Ming et al. (1989) unambiguously detected ${ }^{12} \mathrm{C} /{ }^{13} \mathrm{C}=156$ in SiC from the Murchison CM-chondrite. Since the sample was a $\mathrm{SiC}$ aggregate and not a single grain, Ming et al. infer much higher ratios for some components of the aggregate. Moreover, Zinner et al. (1990) most recently found graphite in the Murchison carbonaceous chondrite, with ${ }^{12} \mathrm{C} /{ }^{13} \mathrm{C}$ up to about 5000 ! The isotopically ultra-light carbon probably was produced in He-burning or explosive H-burning processes (Ash et al., 1988; Ming et al., 1989; Zinner et al., 1990). In Murchison, the ultra-light $C$ was found separately, comprising 


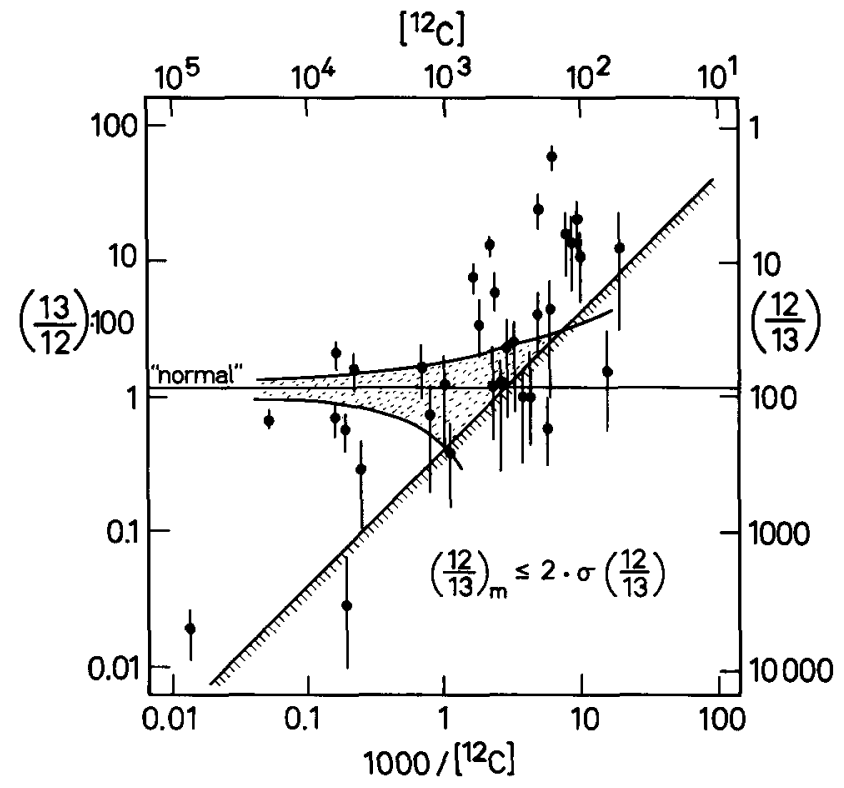

Figure 4. Ratios of the ion intensities measured at 12 and 13 amu versus the reciprocal number of carbon atoms. The uncertainties of the ratios are calculated from the square roots of the involved intensities. In the lower right corner of the diagram, the uncertainties are larger than the ratios themselves, and data in this area are upper limits only. Also indicated is the range, in which data points would have to be considered normal $\left({ }^{12} \mathrm{C} /{ }^{13} \mathrm{C}=\right.$ 89.91 ) within $2 \sigma$ error limits. Ratios above normal may be perturbed by molecular interference of ${ }^{12} \mathrm{CH}^{+}$at $13 \mathrm{amu}$. The few ratios below the normal area may be real isotopic ratios of carbon (see text).

only 0.3 wt.ppm of the meteorite, and it is astonishing that it appears in a sample of not more than $33 \mathrm{C}$-rich grains from Halley. Some of Halley's carbon, contained in refractory phases, clearly is extremely light $\left({ }^{12} \mathrm{C} /{ }^{13} \mathrm{C} \approx 5000\right)$ and thus is isotopically drastically different from the heavy carbon in gaseous CN (Wyckhoff and Lindholm (1989).

Figure 5 shows the measured mass spectrum of the grain with a (12/13)-ion ratio of about 5000 , together with a synthetic spectrum calculated with a normal isotopic composition of the elements. While the deviations from normal are small for most elements, the excess at 12 amu is dramatic. The grain is a typical (CHON + silicate)-grain with 69 atom\% C, 2 atom $\% \mathrm{~N}$, and 17 atom $\% \mathrm{O}$. The silicate component contains about equal amounts of $\mathrm{Fe}$ and $\mathrm{S}$ (3.7 atom\% Fe and 3.2 atom\% S), equal amounts of $\mathrm{Mg}$ and $\mathrm{Si}$ (2.5 atom\% $\mathrm{Mg}$ and 2.2 atom\% $\mathrm{Si})$ and, in addition, traces of $\mathrm{Ni}(0.3$ atom\%) and $\mathrm{Ca}(0.06$ atom\%). It may well be that the silicate component, which comprises about $30 \mathrm{wt} \%$ of the particle, consists of FeS and an Fe-poor pyroxene with some FeNi. 


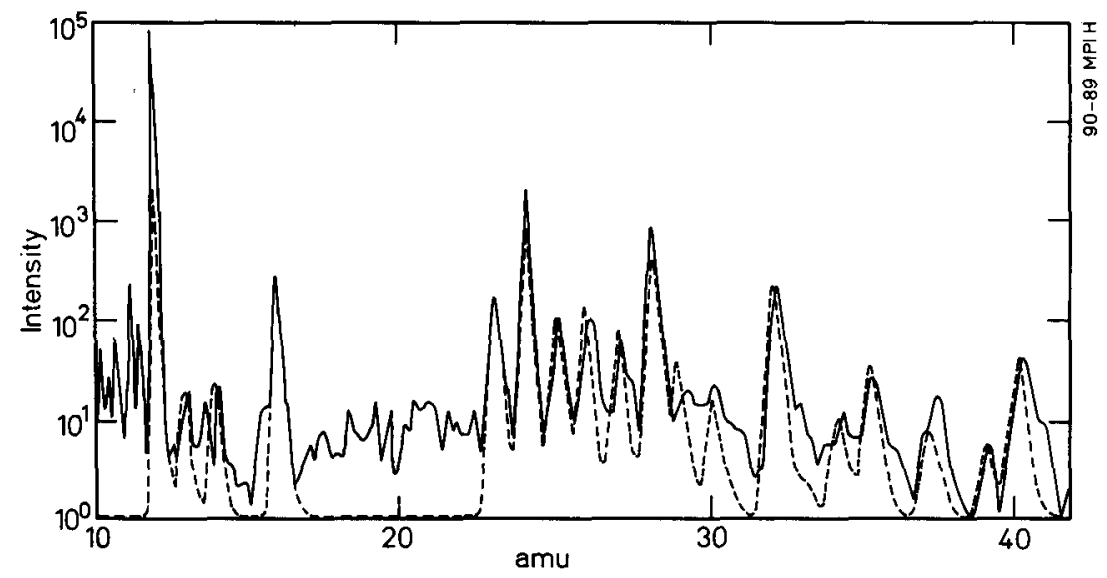

Figure 5. Region of interest of the original measured spectrum \#52407 from PUMA 1 (solid line). The broken line is a synthetic spectrum to show the normal isotopic composition of the elements. Note the logarithmic intensity scale. Either the elements $\mathrm{N}, \mathrm{O}, \mathrm{Na}$, $\mathrm{Al}$, and $\mathrm{K}$ (main lines at 14,16,23, 27, and $39 \mathrm{amu}$, respectively) are mono-isotopic or the rare isotope(s) are too rare to be seen. While the elements $\mathrm{Mg}(24,25,26 \mathrm{amu}), \mathrm{Si}(28$, $29,30 \mathrm{amu}), \mathrm{S}(32,34 \mathrm{amu})$, and $\mathrm{Cl}(35,37 \mathrm{amu})$ (the latter is a target contamination, cf. Jessberger et al., 1988) appear to have normal isotopic composition, $\mathrm{C}(12,13 \mathrm{amu})$ is highly unusual with a large overabundance at $12 \mathrm{amu}$.

\section{Summary}

The principal findings up to now from the time-of-flight mass spectrometers on board Giotto and PUMAs 1 and 2 can be listed as follows:

1. Halley's dust is composed of two end-member components: a refractory organic phase ( $\mathrm{CHON}$ ) and a $\mathrm{Mg}$-rich silicate phase.

2. The CHON component probably is coating silicate cores.

3. The refractory organics are highly unsaturated polycondensates rich in $\mathrm{C}=\mathrm{C}$ and $\mathrm{C}-\mathrm{O}$ compounds.

4. The CHON elements are more abundant than in $\mathrm{CI}$ chondrites. The abundances of $\mathrm{C}$ and $\mathrm{O}$ approach the solar system ( $\equiv$ cosmic) abundances, $\mathrm{N}$ is intermediate between the solar and $\mathrm{CI}$-chondrite abundances, and $\mathrm{H}$ is much closer to the CI-chondrite abundance than to the solar one.

5. Within a factor of two, the abundances of the rock-forming elements are the same as in the whole solar system ( $\equiv$ cosmic).

6. Assuming cosmic ratios for $(\mathrm{C} / \mathrm{Mg})_{\text {dust }}+$ gas and $(\mathrm{O} / \mathrm{Mg})_{\text {dust }}+$ gas, the dust/gas weight ratio of the whole comet is 1.7 , and the elemental composition of the whole comet is estimated (Table 2). 
7. The variations of the elements $\mathrm{Mg}, \mathrm{Si}$, and $\mathrm{Fe}$, as well as the enrichment of volatile elements (relative to CI chondrites), provide a link between Halley's dust and interplanetary dust particles, especially the anhydrous variety.

8. CHON-dominated grains have an average density of $1 \mathrm{~g} / \mathrm{cm}^{3}$, and silicatedominated grains of $2.5 \mathrm{~g} / \mathrm{cm}^{3}$.

9. High (up to 5000) ratios of the ion intensities measured at 12 and $13 \mathrm{amu}$ probably are real ${ }^{12} \mathrm{C} /{ }^{13} \mathrm{C}$-ratios, reflecting nucleosynthetic processes.

The results from the PIA and PUMAs 1 and 2 experiments provided dramatic new insights into the chemistry of comets, about which only few facts and a lot of speculations existed prior to the missions. One should be aware, however, that the data are to be interpreted cautiously, since they cannot be reproduced and are not testable as rigorously as laboratory data are. Therefore, models with too far reaching consequences should be avoided. Still, many questions remain open (Anders, 1986), and they spur on the enthusiasm of the many research groups that are already working for the upcoming CRAF and ROSETTA missions to other comets.

\section{Acknowledgment}

The authors thank F.R. Krueger, D. Maas, and M. Solc for providing unpublished results, and D. Krankowsky for providing critical comments. We also thank M. Hanner and T. Mukai for attentive reviews.

\section{References}

Anders, E. (1986). 'What can meteorites tell us about comets?' In The Comet Nucleus Sample Return Proc. Workshop, Canterbury, U.K., 15-17 July 1986, ed. O. Meliter, ESA SP-249, 31-40.

Anders, E., and Ebihara, M. (1982). 'Solar system abundances of the elements.'

Geochim. Cosmochim. Acta 46, 2363-2380.

Anders, E., and Grevesse, E. (1989). 'Abundances of the elements: Meteoritic and solar.' Geochim. Cosmochim. Acta 53, 197-214.

Antz, Ch. (1988). 'Kombinierte chemische Multielementanalyse interplanetarer Staubteilchen mit Hilfe der Protonenmikrosonde und Synchrotron-RöntgenFluoreszenz,' Diplomarbeit, Max-Planck-Institut für Kernphysik und Universität, Heidelberg, F.R.G., 88.

Antz, Ch., Bavdaz, M., Jessberger, E.K., Knöchel, A., and Wallenwein R. (1987). 'Chemical analysis of interplanetary dust particles with synchrotron radiation.' In Proc. 10th European Regional Astronomy Meeting of the IAU, Praha, Czechoslovakia, Aug. 24-29, 1987, eds. Z. Ceplecha and P. Pecina, Vol. 2, 249-252.

Ash, R.D., Arden, J.W., Grady, M.M., Wright, I.P. and Pillinger, C.T. (1988). 'An interstellar dust component rich in ${ }^{12} \mathrm{C}$.' Nature $\underline{336}, 228-230$.

Audouze J. (1977). 'The importance of CNO isotopes in astrophysics.' In CNO Isotopes in Astrophysics, ed. J. Audouze, Reidel Publ., Dordrecht, Netherlands, 3-11. 
Bradley J.P. (1988). 'Analysis of chondritic interplanetary dust thin-sections.' Geochim. Cosmochim. Acta 52, 889-900.

Brownlee, D.E. (1985). 'Cosmic dust: Collection and research.' Ann. Rev. Earth Planet. Sci. 13, 147-173.

Brownlee, D.E., Wheelock, M.M., Temple, S., Bradley, J.P., and Kissel, J. (1987). 'A quantitative comparison of comet Halley and carbonaceous chondrites at the submicron level.' Lunar Planet. Sci. XVIII, The Lunar Planet. Inst., Houston, Texas, U.S.A., 133-134.

Clark, B.C., Mason, L.W., and Kissel, J. (1986). "Systematics of the "CHON" and other light-element particle populations in comet Halley.' In 20th ESLAB Symposium on the Exploration of Halley's Comet, Heidelberg, F.R.G., 27-31 October 1986, ESA SP-250, 353-358.

Clark, B.C., Mason, L.W., and Kissel, J. (1987). 'Coma particle type occurrences: Evidence for chemical heterogeneity in comet Halley.' Lunar Planet. Sci. Conf. XVIII, Lunar Planet. Science Institute, Houston, Texas, U.S.A., 177-178.

Delsemme, A.H. (1982). 'Chemical composition of nuclei.' In Comets, ed. L.L. Wilkening, University of Arizona Press, Tucson, Arizona, U.S.A., 85-130.

Geiss, J. (1987). 'Composition measurements and the history of cometary matter.' Astron. Astrophys. 187, 859-866.

Greenberg J.M. (1982). 'What are comets made of? A model based on interstellar dust.' In Comets, ed. L. Wilkening, University of Arizona Press, Tucson, Arizona, U.S.A., 163-189.

Grün, E., and Jessberger, E.K. (1990, in press). 'Dust.' In Physics of Comets in the Space Age, ed. W. Huebner, Springer Verlag, Heidelberg, F.R.G.

Jessberger, E.K., Kissel, J., Fechtig, H., and Krueger, F.R. (1986). 'On the average chemical composition of cometary dust.' In The Comet Nucleus Sample Return Proc. Workshop, Canterbury, U.K., 15-17 July 1986, ed. O. Meliter, ESA SP-249, 27-30.

Jessberger, E.K., and Kissel, J. (1987). 'Bits and pieces from Halley's comet.' Lunar Planet. Sci. Conf. XVIII, Lunar Planet. Science Institute, Houston, Texas, U.S.A., 466-467.

Jessberger, E.K., Kissel, J., Fechtig, H., and Krueger, F.R. (1987). 'On the average chemical composition of cometary dust.' In Physical Processes in Comets, Stars, and Active Galaxies, eds. W. Hillebrandt, E. Meyer-Hofmeister, and H.C. Thomas, Springer, Heidelberg, F.R.G., 26-33.

Jessberger, E.K., Christoforidis, A., and Kissel, J. (1988). 'Aspects of the major element composition of Halley's dust.' Nature 332, 691-695.

Jessberger, E.K., Rahe, J., and Kissel, J. (1989). 'The composition of comets.' In Origin and Evolution of Planetary and Satellite Atmospheres, eds. S.K. Atreya, J.B. Pollak, and M.S. Matthews, University of Arizona Press, Tucson, Arizona, U.S.A., 167-191.

Kissel, J. (1986). 'The Giotto particulate impact analyser.' In ESA SP-1077, 67-68.

Kissel, J., et al. (1986a). 'Composition of comet Halley dust particles from Vega observations.' Nature 321, 280-282.

Kissel, J., et al. (1986b). 'Composition of comet Halley dust particles from Giotto observations.' Nature 321, 336-338. 
Kissel, J., and Krueger, F.R. (1987a). 'The organic component in dust from comet Halley as measured by the PUMA mass spectrometer onboard Vega 1.' Nature 326 , 755-760.

Kissel J., and Krueger, F.R. (1987b). 'Ion formation by impact of fast dust particles and comparison with related techniques.' Appl. Phys. A 42, 69-85.

Krankowsky, D., and Eberhardt, P. (1989, in press). 'Evidence for the composition of ices in the nucleus of comet Halley.' In Comet Halley 1986, World-Wide Investigations, Results, and Interpretations, Ellis Horwood Ltd., Chichester, U.K.

Krueger, F.R., and Kissel, J. (1987). 'The chemical composition of the dust of comet P/Halley as measured by "PUMA" on board VEGA-1.' Naturwissenschaften 74, 312316.

Krueger, F.R., and Kissel, J. (1989). 'Biogenesis by cometary grains-thermodynamic aspects of self-organization.' Origins of Life and Evol. of the Biosphere 19, 87-93.

Krueger, F.R., Korth, A., and Kissel, J. (1990, in press). 'The organic matter of comet P/Halley as inferred by joint gas and solid phase analysis.' Nature.

Lamy, Ph., and McDonnell, J.A.M., and Pankiewicz, G.S. (1990). 'Physical properties in cometary dust.' In this volume.

Langer, W.D., Graedel, T.E., Frerking, M.A., and Armentrout, P.B. (1984). 'Carbon and oxygen isotope fractionation in dense interstellar clouds.' Astrophys. J. 277, 581604.

Langevin, Y., Kissel, J., Bertaux, J.-L., and Chassefiere, E. (1987a). 'First statistical analysis of 5000 mass spectra of cometary grains obtained by PUMA 1 (Vega 1) and PIA (Giotto) impact ionization mass spectrometers in the compressed modes.' Astron. Astrophys. 187, 761-766.

Langevin, Y., Kissel, J., Bertaux, J.-L., and Chassefiere E. (1987b). 'Impact ionization mass spectrometry of cometary grains on board Giotto, Vega 1 and Vega 2 spacecrafts: Preliminary statistical analysis of spectra in compressed modes.' Lunar Planet. Sci. Conf. XVIII, The Lunar Planet. Inst., Houston, Texas, U.S.A., 533-534.

Lawler, M.E., Brownlee, D.E., Temple, S., and Wheelock, M.M. (1989a). 'Iron, magnesium, and silicon in dust from comet Halley.' Icarus 80 , 225-242.

Lawler, M.E. (1989b, in press). 'Mass-composition relationships in dust particles from comet Halley.' Icarus; presented at Comets in the Post-Halley Era, Bamberg, F.R.G., April 24-28, 1989.

Maas, D., Krueger, F.R., and Kissel, J. (1990, in press). 'Mass and density of silicateand CHON-type dust particles released by comet P/Halley.' In Asteroids, Comets, and Meteors III, eds. C.-I. Lagerkvist, H. Rickman, B.A. Lindblad, and M. Lindgren, Reprocentralen HSC, Uppsala, 12.6-16.6.

Millman, P.M.(1977). 'The chemical composition of cometary meteoroids.' In Comets, Asteroids, Meteorites, ed. A.H. Delsemme, University of Toledo, Ohio, U.S.A., 127132.

Ming, T., Anders, E., Hoppe, P., and Zinner, E. (1989). 'Meteoritic silicon carbide and its stellar sources; implications for galactic chemical evolution.' Nature, 339, 351-354.

Mukhin, L.M., Evlanov, E.N., Fomenkova, M.N., Khromov, V. N., Kissel, J., Priludski, O.F., Zubkov, B.V., and Sagdeev, R.Z. (1987). 'Different types of dust particles in Halley's comet.' Lunar Planet. Sci. Conf. XVIII, The Lunar Planet. Inst., Houston, Texas, U.S.A., 674-675. 
Mukhin, L.M., Dikov, Yu. P., Evlanov, E.N., Fomenkova, M.N., Nazarov, M.A., Priludsky, O.F., Sagdeev, R.Z., and Zubkov, B.V. (1989a). 'Possible composition of Halley comet dust (Si-poor particles) according to the data obtained by massspectrometer PUMA-2.' Lunar Planet. Sci. Conf. XX, The Lunar Planet. Inst., Houston, Texas, U.S.A., 733-734.

Mukhin, L.M., Dikov, Yu. P., Evlanov, E.N., Fomenkova, M.N., Nazarov, M.A., Priludsky, O.F., Sagdeev, R.Z., and Zubkov, B.V. (1989b). 'Possible composition of Halley comet dust (Si-rich particles) according to the data obtained by massspectrometer PUMA-2.' Lunar Planet. Sci. Conf. XX, The Lunar Planet. Inst., Houston, Texas, U.S.A., 735-736.

Rietmeijer, F.J.M., Mukhin, L.M., Fomenkova, M.N., and Evlanov, E.N. (1989). 'Layer silicate chemistry in P/comet Halley from PUMA-2 data.' Lunar Planet. Sci. Conf. XX, The Lunar Planet. Inst., Houston, Texas, U.S.A., 904-905.

Rickman, H. (1986). 'Masses and densities of comets Halley and Kopff.' In The Comet Nucleus Sample Return Proc. Workshop, Canterbury, U.K., 15-17 July 1986, ed. O. Meliter, ESA SP-249, 195-205.

Sagdeev, R.Z., Kissel, J., Evlanov, E.N., Mukhin, L.M., Zubkov, B.V., Priludski, O.F., and Fomenkova, M.N. (1986). 'Elemental composition of dust component of Halley's comet: Preliminary analysis.' In 20th ESLAB Symposium on the Exploration of Halley's Comet, Heidelberg, F.R.G., 27-31 October 1986, ESA SP-250, Vol. III, 349-352.

Solc, M., Vanysek, V., and Kissel, J. (1986). 'Carbon stable isotopes in comets after encounters with P/Halley.' In 20th ESLAB Symposium on the Exploration of Halley's Comet, Heidelberg, F.R.G., 27-31 October 1986, ESA SP-250, 373-376.

Solc, M., Jessberger, E. K., Hsiung, P., and Kissel, J. (1987). 'Halley dust composition.' In Proc. 10th European Regional Astronomy Meeting of the IAU, Praha, Czechoslovakia, Aug. 24-29, 1987, eds. Z. Ceplecha and P. Pecina, Vol. 2, 47-51. Solc, M., Jessberger, E.K. and Kissel, J. (1989). Unpublished data.

Sutton, S.R., and Flynn, G.J. (1988). 'Stratospheric particles: Synchrotron X-ray fluorescence determination of trace element contents.' Proc. XVIII Lunar. Planet. Sci. Conf., Cambridge Univ. Press, Cambridge, Massachusetts, U.S.A., 607-613.

van der Stap, C.C.A.H., Vis, R.D. and Verheul, H. (1986). 'Interplanetary dust: Arguments in favour of a late stage nebular origin.' Lunar Planet. Sci. XVII, The Lunar and Planetary Institute, Houston, Texas, U.S.A., 1013-1014.

Wäsch, R. (1986). 'An approach to the nature of the silicatic component of the comet Halley.' In 20th ESLAB Symposium on the Exploration of Halley's Comet, Heidelberg, F.R.G., 27-31 October 1986, ESA SP-250, 265-267.

Wallenwein, R., Antz, Ch., Jessberger, E.K., and Traxel, K. (1987). 'Proton microprobe analysis of interplanetary dust particles.' In Proc. 10th European Regional Astronomy Meeting of the IAU, Praha, Czechoslovakia, Aug. 24-29, 1987, eds. Z. Ceplecha and P. Pecina, Vol. 2, 245-248.

Wyckhoff, S., and Lindholm, E. (1989). 'On the carbon and nitrogen isotope abundance ratios in comet Halley.' Adv. Space Res. 2, 151-155.

Zinner, E, Wopenka, B., Amari, S., and Anders, E. (1990). 'Interstellar graphite and other carbonaceous grains from the Murchison meteorite: Structures, composition and isotopes of C, N, and Ne.' Lunar Planet. Sci. XXI, The Lunar and Planetary Institute, Houston, Texas, U.S.A., 1255-1256. 
Zinner, E., and Epstein, S. (1987). 'Heavy carbon in individual grains from the Murchison meteorite.' Earth Planet. Sci. Lett. 84, 359-368 (1987).

Zinner, E. (1989, in press). 'Isotopic measurements with the ion microprobe.' Proc. Workshop New Frontiers in Stable Isotope Research, USGS Bulletin, Washington, D.C., U.S.A..

Zolensky, M.E., Lindstrom, D.J., Thomas, K.L., Lindstrom, R.M., and Lindstrom, M.M. (1989). "Trace element compositions of six "chondritic" stratospheric dust particles.' Lunar Planet. Sci. XX, The Lunar and Planetary Institute, Houston, Texas, U.S.A., 1255-1256. 